\section{POLÍTICA EUROPEA DE SEGURIDAD Y DEFENSA: UNA APROXIMACIÓN MILITAR}

\author{
Félix Sanz Roldán \\ Alto Representante para la Presidencia española \\ de la UE (Defensa). General de Ejército (R)
}

\begin{abstract}
The new century has confirmed the existence of new dangers: transnational terrorism, massive destruction weapons along with the weakening of some states which are nearly broken down. By the end of 2003, the Council of Europe laid the foundations of the European Security Strategy (ESS), and the European Policy for Common Security (EPCS) along with the PESD. The Council defined the geographic areas and the institutional military actors such as the Military Committee of the EU (EUMC) and the EU Military General Staff (EUMGS). Another key element is the European Agency for the Defense. The military capabilities and the Battlegroups (BGs) are studied too.
\end{abstract}

KEY WORDS: European Security Strategy (EsS); European Policy for Common Security (EPCS): Military Committee of the EU; EU Military General Staff; European Agency for the Defense; military capabilities and Battlegroups.

El cambio de siglo ha confirmado, la existencia de nuevos elementos, de ámbito global, como son el terrorismo de carácter transnacional, la proliferación de armas de destrucción masiva y la existencia de Estados en descomposición, que han ampliado sustancialmente el espectro tradicional de riesgos para la estabilidad y seguridad internacional'.

La secuencia de dramáticos atentados de los últimos años ha abierto una profunda reflexión en el seno de las sociedades occidentales sobre el fenómeno terrorista, al constatar las dificultades que padecen nuestros sistemas políticos para combatirlos eficazmente. Esta realidad ha incrementado significativamente la percepción de vulnerabilidad que tienen los ciudadanos.

La combinación del terrorismo con la mayor accesibilidad a nuevas tecnologías y materiales críticos ha supuesto un incremento de los riesgos por empleo de armas de destrucción

\section{EUROPEAN POLITICS OF DEFENSE AND SECURITY: A MILITARY APPROACH}

RESUMEN: El cambio de siglo ha confirmado la existencia de nuevos peligros: terrorismo transnacional, armas de destrucción masiva y la debilidad de algunos estados en práctica descomposición. A finales de 2003, el Consejo Europeo sentó las bases de la Estrategia Europea de Seguridad (EES), y la Política Europea de Seguridad Común (PESC) y el PESD, definiendo las áreas geográficas de actuación y los actores militares institucionales, como son el Comité Militar de la UE (EUMC) y el Estado Mayor de la UE (EUMS). Otro elemento clave es la Agencia Europea de Defensa. Se analizan también las capacidades militares y los BATTTLEGROUPS (BGs).

PALABRAS CLAVE: Estrategia Europea de Seguridad (EES); Política Europea de Seguridad Común (PESC); Comité Militar de la UE; Estado Mayor de la UE; Agencia Europea de Defensa; capacidad militar y BATTTLEGROUPS.

masiva, tanto por su variedad y potencia -al riesgo nuclear se ha añadido con desgraciada facilidad el biológico y químico- como por el aumento de las distancias de su posible empleo, merced a nuevos vectores de lanzamiento basados en el desarrollo de la tecnología de misiles.

En muchas partes del mundo, el mal gobierno, la corrupción sistemática, los conflictos civiles enquistados o la aparición de poderes fácticos que rivalizan con los poderes del Estado, han llevado a un debilitamiento de las estructuras sociales, hasta un nivel de fragilidad en el que los gobiernos se muestran incapaces de mantener el monopolio del uso de la fuerza. La asociación de un Estado en descomposición con la delincuencia organizada produce una peligrosa combinación, susceptible de crear inestabilidad en cualquier entorno geográfico.

Esta breve enunciación de lo que se tiende a considerar como nuevas amenazas convive, y muchas veces se super- 
pone, con el panorama clásico de áreas geográficas de conflictividad, a nivel mundial.

Teniéndolo como "telón de fondo"; hemos orientado el contenido de este artículo aprovechando el detallado análisis que otros colaboradores ofrecen del ámbito de la Política Europea de Seguridad y Defensa. Así, nos ceñiremos a aquellos aspectos que hemos considerado particularmente significativos que estimamos pueden marcar el futuro, a corto y medio plazo, de los aspectos relacionados con la participación militar de España en materia de gestión de crisis liderada por la UE.

\section{La Estrategia Europea de Seguridad}

A finales de 2003, el Consejo Europeo adoptó el documento presentado por Javier Solana ${ }^{2}$ que contiene las bases de la Estrategia Europea de Seguridad (EES) ${ }^{3}$. Dicho documento define los principios en los que se debe basar el esfuerzo de una Europa, dispuesta a asumir papel relevante en el mantenimiento de la seguridad mundial, partiendo de la base de que la UE es un actor de envergadura global, cada vez más creíble y eficaz, gracias a los intereses convergen- tes de sus Estados miembros y al creciente fortalecimiento de la solidaridad entre ellos.

La EES identifica nuevos desafíos para la seguridad, fruto de la mayor apertura de las fronteras y de la evolución económica, tecnológica, politica y social, que han hecho posible la aparición de nuevos actores internacionales, que carecen de carácter estatal. En este entorno surge, como idea clave, la de identificar la seguridad como uno de los principales condicionantes del desarrollo que permitirá romper el ciclo conflicto-inseguridad-pobreza que caracteriza a numerosas situaciones de crisis.

La aparición de nuevas y diversificadas amenazas, menos visibles y previsibles que las presentes, durante la guerra fría, requieren una respuesta común de la $U E$, sin perder de vista el hecho de que -en esta época de globalización-, las amenazas lejanas pueden ser tan inquietantes como las próximas.

En este sentido, la EES establece tres objetivos estratégicos. El primero es hacer frente a las amenazas de una manera activa. Dado que las nuevas amenazas no tienen un carácter puramente militar, implica el empleo combinado de medios diversos -militares, diplomáticos, económicos,

Figura 1. Los pilares de la Unión Europea. Encuadramiento de la PESD.

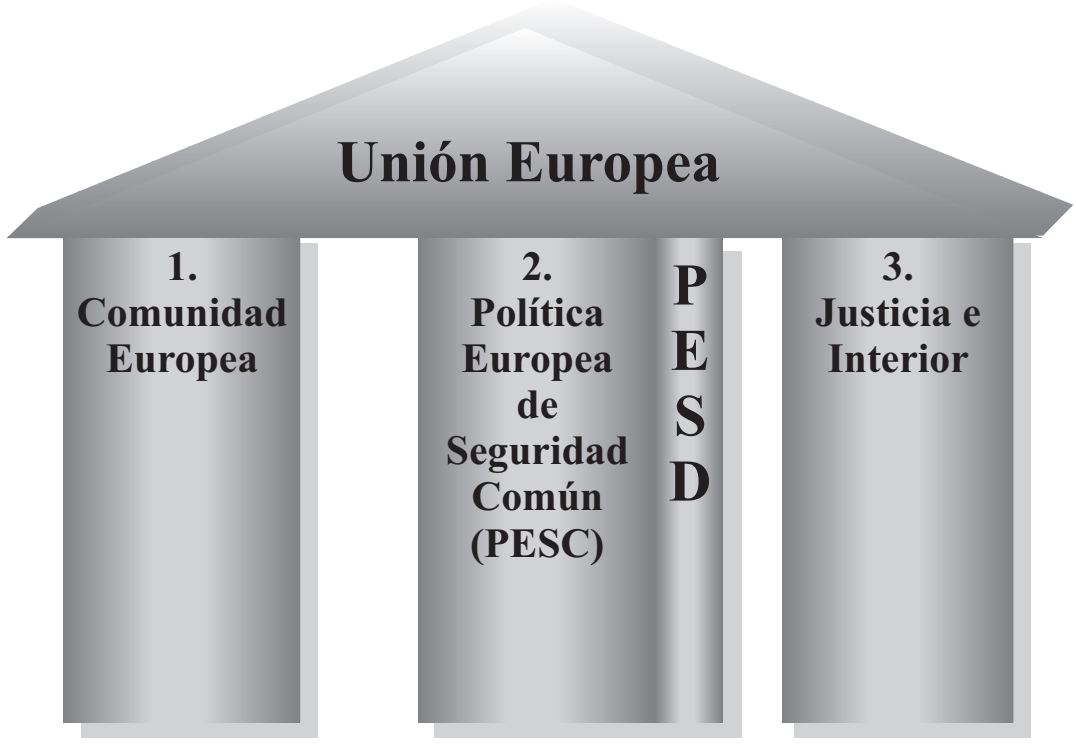


policiales, etc.- para los que la UE está especialmente preparada. El nuevo concepto de autodefensa frente a unas amenazas caracterizadas por su dinamismo, se basa en la necesidad de estar preparados para actuar antes de que llegue a producirse la crisis y supone, en muchos casos, establecer la primera línea fuera del territorio de la UE.

El segundo objetivo estratégico es extender la seguridad a los países vecinos. Las crisis que pueden desarrollarse en países vecinos se transforman en problemas para Europa. Por ello, ha de promoverse un conjunto de países bien gobernados al este de sus fronteras, que evite la aparición de nuevas líneas divisorias en Europa, y en la orilla del Mediterráneo donde existe un fuerte compromiso en el marco del proceso de Barcelona. El tercer objetivo es el establecimiento de un orden internacional basado en un multilateralismo eficaz, que debe llevar al desarrollo de una sociedad internacional más fuerte, con instituciones que funcionen adecuadamente y de un orden internacional basado en el Derecho. Se reconoce la Carta de las Naciones Unidas como marco fundamental para las relaciones entre Estados, siendo su Consejo de Seguridad el organismo responsable de mantener la paz y la seguridad internacionales. En este ambiente, el mantenimiento de las relaciones transatlánticas, de las que la OTAN es un referente clave, constituye un elemento central que refuerza la seguridad en el ámbito internacional, seguridad que, como base del desarrollo, también ha de buscarse a través de la cooperación y el apoyo de otras Organizaciones Regionales de Seguridad. Todo esto tiene unas implicaciones estratégicas para Europa que, para hacer valer su potencial, ha de actuar de una forma más activa y más coherente, aumentar sus capacidades y mejorar su cooperación.

El aumento del peso político de la UE en el panorama internacional, implicará la asunción de más responsabilidades y de un papel más activo, reforzando su contribución a la labor de mantenimiento de la paz y seguridad internacionales y a la gestión de crisis. Para lograrlo, ha de dotarse de capacidades civiles y militares que le permitan intervenir de forma temprana, rápida, eficaz y, si es preciso, contundente en varias operaciones simultáneamente.

Esta mayor implicación europea en materia de seguridad, puede articularse a través de los dispositivos permanentes UE-OTAN, que refuerzan la capacidad operativa de la Unión y proveen del marco de asociación estratégica entre ambas, en materia de gestión de crisis. Pero esto no será bastante en el futuro y la UE debe buscar su autosuficiencia en el campo de la seguridad y la defensa. Los ejércitos europeos estarán constituidos por fuerzas más móviles y más flexibles, para lo que serán necesarios mayores recursos para la defensa y usarlos de forma más eficaz. El empleo de medios, puestos en común y compartidos, permitirá incrementar las capacidades para actuar. Pero no sólo es necesario mejorar las capacidades puramente militares, también hay que incrementar notablemente la capacidad de aportar recursos civiles para la resolución de situaciones de crisis, así como la capacidad diplomática de la Unión y la comunicación en materia de inteligencia entre los Estados miembros. Este aumento de capacidades podría permitir la ampliación de la gama de misiones en que interviene la UE.

En materia de coherencia, el desafío consiste en reunir los distintos instrumentos y capacidades, tanto los comunes como los que permanecen en poder de los Estados miembros, de forma que se logre una mayor concurrencia, no sólo en las actuaciones propias de la Unión, sino también en las actuaciones exteriores de cada Estado.

Desde nuestra perspectiva, la EES describe un entorno en el que la respuesta europea en materia de seguridad rara vez tendrá un carácter estrictamente militar, aunque el empleo de medios militares en combinación con otros será frecuente. Consideramos de esencial importancia que, tal como se establece en el punto 3 de nuestra Directiva de Defensa Nacional (DDN) 1/04, la actuación de nuestras Fuerzas Armadas en operaciones desarrolladas en el ámbito de la Política Europea de Seguridad y Defensa (PESD) exigirá una decisión previa de Naciones Unidas u otra organización internacional de las que España forma parte y la aprobación del Parlamento español. Asimismo, y con independencia del carácter que puedan tener las operaciones futuras, los organismos militares deberán mantener un papel activo en el proceso de toma de decisiones, sobre todo cuando se considere el empleo de capacidades militares.

\section{ÁreAs GEOGRÁfICAS de ACtUACIÓN}

El hecho de que la PESD mira hacia África con particular atención no ofrece dudas. Puede constatarse revisando el 
contenido de las agendas de las Instituciones europeas que tratan asuntos de Política Exterior y de Seguridad Común (PESC), o advirtiendo la reciente proliferación de misiones de observadores y asesores de la UE en zonas africanas en crisis (Darfur, Somalia, República Democrática del Congo,...). Desde el nacimiento de la Unión Africana en julio de 2002, la UE ha tenido especial interés en patrocinar los esfuerzos de esta y otras organizaciones regionales africanas, a través de una cooperación estratégica que, en el ámbito de la PESD, tiene su reflejo en el Plan de Acción de respaldo a la paz y seguridad en África, aprobado en noviembre de 2004. La contribución militar a este Plan se encuadra principalmente en la participación de oficiales en misiones de reconocimiento ${ }^{4}$, asesoramiento en temas de desarme, desmovilización y reinserción ${ }^{5}$, reformas del sector seguridad ${ }^{6}$, y apoyo a tareas de planeamiento de otras organizaciones.

Sin embargo, la vocación de la UE como actor global en temas de seguridad internacional obliga a un cuidadoso estudio e implicación en otros escenarios. Así, a raíz de la crisis surgida con motivo del maremoto que arrasó las costas del océano Índico en las navidades de 2004, la
UE se implicó en el proceso de paz de Indonesia entre la guerrilla rebelde de la región de Aceh y el gobierno dando pie a la puesta en marcha de una misión de supervisión de los acuerdos de paz en esta zona ${ }^{7}$. Esta misión, de carácter civil, encuadró sin embargo un significativo número de militares entre su personal (entre los que se incluyó un pequeño contingente de oficiales españoles y el propio Jefe de Operaciones de la misión).

No podemos olvidar, asimismo, el actual empeño de fuerzas militares europeas en Bosnia-Herzegovina (operación Althea, iniciada a finales de 2004), enmarcado en la especial sensibilidad que la UE tiene hacia los países balcánicos. Este esfuerzo militar, que podría ampliarse asumiendo responsabilidades en Kosovo, refuerza la línea de acción europea que inició su andadura en 2003 con el establecimiento de la misión de Policía en Bosnia-Herzegovina (EUPM) y la primera misión militar de la UE (operación Concordia) en la Antigua República Yugoslava de Macedonia (FYROM).

Por último, cabria indicar que la puesta en marcha de recientes misiones de carácter civil en lugares conflictivos como el Cáucaso y Oriente Próximo ${ }^{8}$, demuestra una vo-

Figura 2. Operaciones y misiones de la UE.

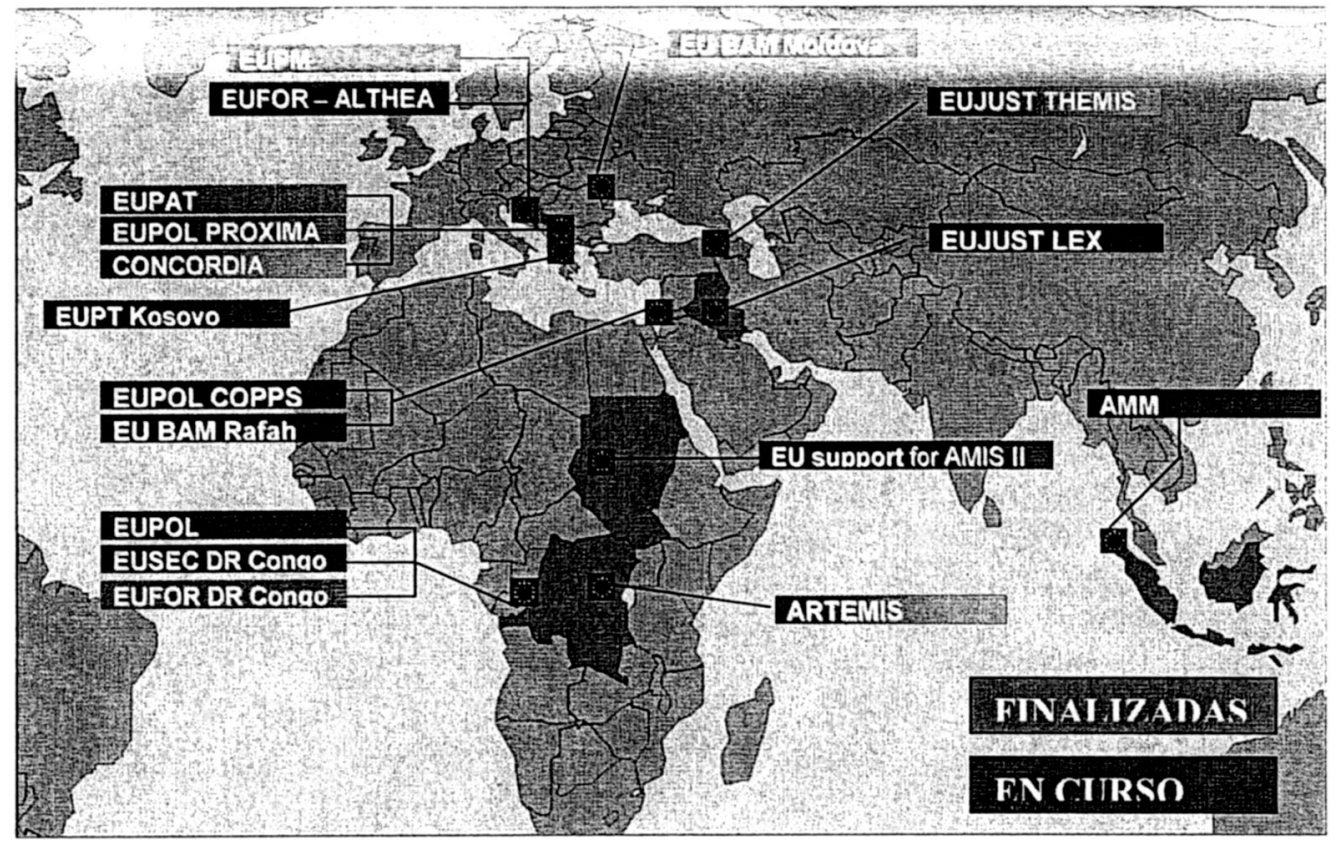


cación más amplia de la PESD y el claro afianzamiento de la EES en su aplicación cotidiana.

Hemos hecho una somera referencia a aquellas operaciones de la UE con implicaciones militares, ya sea por sus cometidos o en virtud del personal o medios aportados. En este sentido, vemos con atención la participación creciente de personal y medios militares en misiones de carácter civil. La aptitud de los medios militares para su utilización en crisis y emergencias, de cualquier tipo, es un elemento que estimula y enorgullece a la institución militar, vinculada por vocación y compromiso al servicio de su sociedad. Desde nuestra perspectiva, por tanto, parece adecuada una mayor concienciación y especialización de nuestro personal en temas de carácter internacional que se salen de la clásica formación militar. El cúmulo de misiones, su variedad y el amplio espectro geográfico de actuación permiten entrever un futuro lleno de retos, a los que habrá que dirigir un particular interés debido a que, cada vez con mayor énfasis, se abre la posibilidad de participar tanto mediante el empleo de unidades militares, como con personal militar formando parte de equipos especializados.

\section{LOS ACTORES MILITARES INSTITUCIONALES EN EL ÁMBITO DE LA PESD}

\section{Estructuras militares permanentes}

En el seno de la PESD, los aspectos militares de gestión de crisis se sustentan en la existencia de órganos específicos. Son el Comité Militar de la UE (EUMC) y el Estado Mayor de la UE (EUMS).

El Comité Militar se encuentra en un momento en el que pugna por reafirmarse en sus cometidos, aprobados en el año 2001, con la puesta en marcha de las estructuras PESD. Los nuevos retos planteados desde entonces, y los previsibles a corto y medio plazo, ponen al EUMC en la tesitura de mantener su sitio en el entramado de la Política Europea de Seguridad y Defensa. El EUMC tiene que hacer sentir su presencia y su valor. Sólo de esa manera el resto de las Instituciones valorarán la importancia y utilidad de contar con un Comité en el que están representados, al más alto nivel, los militares de todos los Estados miembros. De otro modo se corre el riesgo de que los medios militares

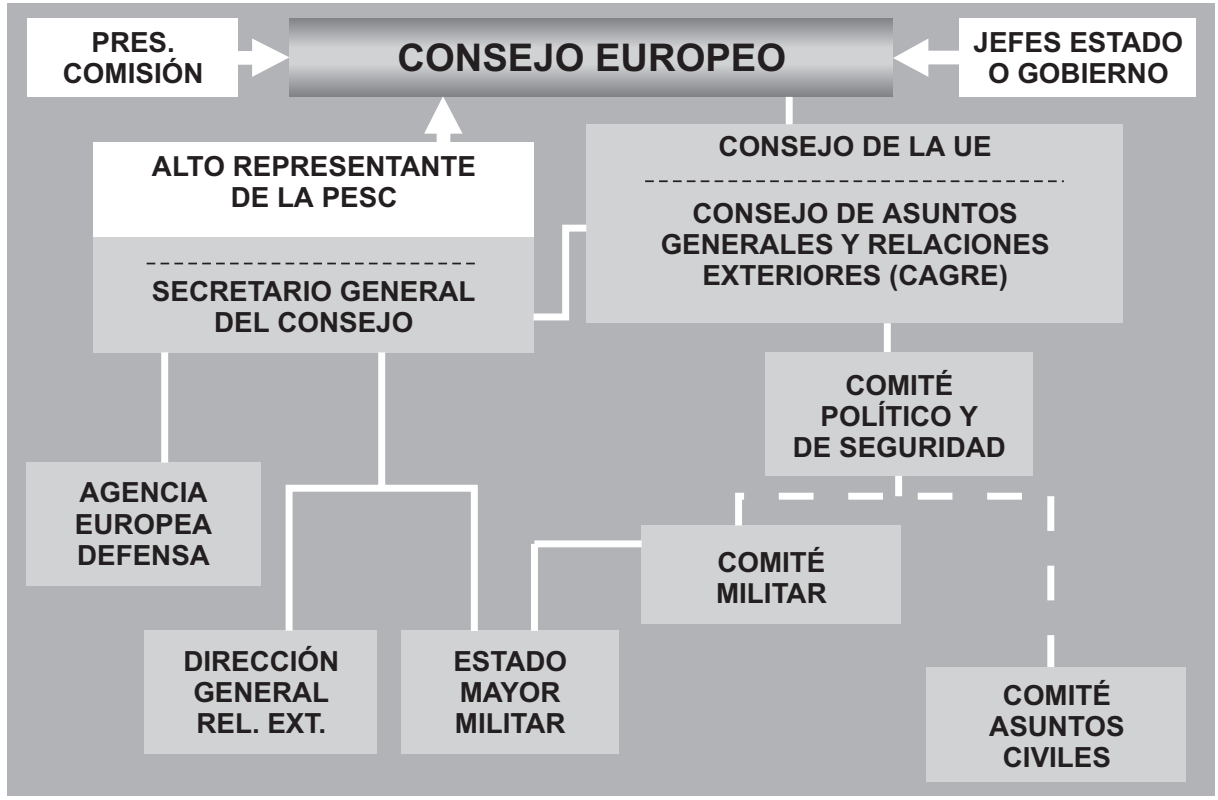


de las naciones acaben siendo empleados sin contar con la dirección técnica y el asesoramiento adecuados. Consideramos, por tanto, fundamental el respaldo al importante y necesario papel del EUMC en el ámbito de los mecanismos de toma de decisión de la PESD.

Por su parte, el Estado Mayor de la UE (EUMS) está cobrando cada vez un mayor protagonismo en el seno de la Secretaría General del Consejo. Esta situación viene propiciada por diversos factores, entre ellos, la progresiva implicación de la UE en temas de gestión de crisis con posible uso de medios militares, y su potenciación en el ámbito del planeamiento integral ${ }^{9}$. A lo largo de 2005 se han producido dos procesos significativos para el futuro de este organismo, relacionados con su capacidad para cumplir los cometidos asignados y su mayor o menor subordinación al EUMC: la creación en su seno de la Célula Cívico-Militar (CIV-MIL Cell) y la revisión de sus cometidos (Términos de Referencia), con la incorporación de nuevas tareas que no se contemplaban cuando se creó en el año 2001.

De la misma manera que hace no demasiados años se impuso la concepción de que las operaciones militares deberían tener, en la mayor parte de los casos, carácter conjunto, en contraposición a su naturaleza específica tradicional, la tendencia actual es que las operaciones futuras sean cívico-militares, de forma que se aproveche la sinergia de las actuaciones de ambos componentes. La CIV-MIL Cell surge, pues, con la intención de servir de elemento responsable de llevar a cabo el planeamiento cívico-militar de gestión de crisis. Se trata, por tanto, de una iniciativa innovadora sobre la que la UE en su conjunto tiene depositadas muchas expectativas. Asimismo, y como consecuencia de la búsqueda de una solución de compromiso a la fallida propuesta de un grupo reducido de países, que pretendian crear un Cuartel General permanente de la UE ${ }^{10}$, a la CIV-MIL Cell se le ha asignado también el cometido de constituir el embrión del Centro de Operaciones de la UE (OPSCEN). Se pretende así tener capacidad autónoma para conducir operaciones de una entidad similar a la operación ARTEMIS (RDC) ${ }^{11}$ cuando no se recurra a estructuras OTAN o a cuarteles generales nacionales ofrecidos a la UE. La Célula se ha activado a lo largo del año 2005, y se prevé que la infraestructura y medios necesarios para la activación del OPSCEN estén disponibles a partir del verano de este año.
La generación del OPSCEN ha supuesto el fin de un conflicto más próximo al ámbito político que al puramente técnico militar. España, que tenía un interés primordial en la puesta en marcha de la CIV-MIL Cell y que propuso su creación, sabe que generará un nuevo valor añadido en la capacidad de la UE para llevar a cabo planeamiento de contingencia $^{12}$ y de respuesta ante crisis $y$, muy en particular, en la faceta de integración de capacidades civiles y militares. Desde esta perspectiva consideramos importante la máxima potenciación de la CIV-MIL Cell en todos aquellos aspectos que refuercen sus capacidades previstas de planeamiento cívico-militar.

\section{La Agencia Europea de Defensa}

Otro elemento clave en la construcción del sector de seguridad y defensa europeo lo constituye la Agencia Europea de Defensa (EDA). Tiene como misión apoyar al Consejo y a los Estados miembros en su esfuerzo para mejorar las capacidades de defensa para la gestión de crisis y apoyar la PESD. Está dirigida personalmente por el Secretario General/Alto Representante para la PESC (SG/AR), quien también preside el Comité de Dirección. Éste adopta distintas formaciones $^{13}$, y actúa bajo la autoridad del Consejo y en el marco de sus directrices.

La EDA continúa dando pasos dentro de su propio proceso de establecimiento, con vistas a alcanzar su plena capacidad operativa. Hasta la fecha ha iniciado, con la ayuda del EUMS, una serie de proyectos en el área del desarrollo de capacidades, y se considera que esta relación entre el EUMS y la EDA debe ser habitual en el futuro. Asimismo, la agencia está trabajando, junto al EUMC, en el Proceso de Desarrollo Global de Capacidades. La lógica progresión en la estructura y procedimientos de la EDA debe estar perfectamente sincronizada con la delimitación de sus cometidos en el ámbito de la identificación y desarrollo de capacidades militares. En este sentido, debería extremarse al máximo la coordinación de esfuerzos entre el EUMC y la Agencia, con el objeto de evitar o duplicidades que resten cometidos a este último organismo o que invadan el ámbito de actuación del primero.

\section{Procedimientos de gestión de crisis de la UE}

La puesta en marcha de las estructuras PESD motivó la creación de unos procedimientos que regularan las relacio- 
nes y responsabilidades de los diferentes actores en materia de gestión de crisis $^{14}$. La complejidad del entramado institucional y la exigencia del consenso intergubernamental, como norma general para cualquier actuación enmarcada en el ámbito de la Política Exterior y de Seguridad Común, propiciaron un cauce sinuoso y muy burocrático, que se traduce normalmente en una muy limitada capacidad de respuesta ante situaciones imprevistas. Su aplicación, hasta la fecha, en el ámbito de operaciones militares lideradas por la UE, ha demostrado la necesidad de una adecuada revisión para hacer frente, como mínimo, a la gestión de crisis o emergencias que exijan una rápida respuesta.

En la primavera de 2005, el SG/AR presentó durante la reunión informal de Ministros de Defensa, celebrada en Luxemburgo, una propuesta sobre un procedimiento abreviado de planeamiento y toma de decisiones para operaciones de respuesta rápida ${ }^{15}$. Se intentaba cubrir así la citada carencia en los procedimientos de gestión de crisis de la UE para este tipo de operaciones. El aspecto esencial y el más preocupante desde la perspectiva militar de dicha propuesta, radica en la desaparición de la actuación del EUMC como órgano colegiado en el proceso de toma de decisiones, aunque se mantiene el papel asesor de los Representantes Militares dentro de las Delegaciones nacionales que asisten a las reuniones del Comité Político y de Seguridad (COPS). Por otra parte, y siguiendo un mandato del Consejo de la UE -en su formato de Justicia y Asuntos de Interior- tras los atentados terroristas en Londres, durante el verano de 2005, la Secretaría General del Consejo (SGC) ha desarrollado unos procedimientos para compartir información, asegurar la coordinación y posibilitar la toma de decisiones ante cualquier tipo de emergencia ${ }^{16}$. Los acuerdos que contempla este documento no se ciñen únicamente a la lucha contraterrorismo, sino que proporcionan un marco aplicable a todo tipo de crisis, tales como desastres naturales, accidentes industriales 0 emergencias de tipo sanitario (pandemias...). Manteniendo el principio de flexibilidad para adaptarse a cada tipo particular de emergencia, el mecanismo que se prevé contempla un grupo de alto nivel de dirección de crisis (Presidencia de turno, el SG/AR, Comisión y Estados miembros afectados), un organismo UE con capacidad para tomar decisiones o acordar acciones coordinadas (COREPER/CONSEJO) y una maquinaria de apoyo basada en los servicios de la Secretaría General del Consejo y de la Comisión, reforzada con los expertos nacionales pertinentes. En el documento no se hace referencia específica a la participación militar en el planeamiento y gestión, más allá de una mera referencia a la existencia de estructuras clave en el seno de la $U_{E_{1}}$ aunque sin identificar cometidos.

Desde la perspectiva ya reflejada en párrafos anteriores, estimamos que la necesidad de optimizar los procedimientos de gestión de crisis de la UE no debe llevar consigo una disminución de las funciones y cometidos de los actores institucionales militares, y muy especialmente del EUMC. Esperamos que la flexibilidad genérica propia de los procedimientos y las enseñanzas obtenidas a través de los procesos vigentes de lecciones aprendidas, permitan encauzar, de la forma más adecuada, la solución.

\section{Capacidades militares}

No se puede hacer un análisis del futuro de la PESD sin hacer referencia a un elemento primordial de la misma: Ios medios militares con los que se ha de apoyar. En el marco del planeamiento de capacidades militares, la UE está embarcada en un nuevo ciclo abierto con la aprobación del Objetivo General de Fuerza 2010 (HLG 2010) en junio de 2004, y que da continuidad en el tiempo a los trabajos realizados para cumplimentar el Objetivo General de Helsinki (HHG), aprobado a finales de 1999 y alcanzado con ciertas limitaciones en el año 2003. El horizonte temporal del año 2010 constituye una limitación para la adecuada planificación de capacidades militares a largo plazo. Recogiendo las preocupaciones de los sectores profesionales (tanto civiles como militares) que participan en este proceso, en el seno de las instituciones europeas se ha sentido la necesidad de hacer progresar en esta cuestión.

El Catálogo de Necesidades 2005, aprobado en noviembre de ese mismo año, es el documento que comprende el listado de capacidades militares identificadas para llevar a cabo los cometidos reseñados en el nuevo Objetivo General. A lo largo del año 2006 se llevó a cabo el proceso de recepción de ofertas nacionales que ha permitido elaborar un primer Catálogo de Fuerzas. Configurado éste, se ha comenzado un proceso de identificación de carencias $y_{1}$ en cooperación con la Agencia Europea de Defensa, se ha abordado la elaboración de un plan que permita subsanarlas antes de 2010. 
La participación española en el proceso de desarrollo del HLG 2010 ha sido muy activa desde el inicio de su andadura, intentando obtener, de forma complementaria, enseñanzas aplicables a nuestro planeamiento nacional. Esta labor se está llevando a cabo entre el Estado Mayor de la Defensa (EMAD) y los Cuarteles Generales de los Ejércitos y la Armada con una mentalidad totalmente conjunta, no sólo por las instituciones inmersas en el proceso, sino por el nuevo enfoque cualitativo empleado en la definición de los requisitos militares. Asimismo, se ha tenido en cuenta la compatibilidad con los compromisos adquiridos con otras organizaciones internacionales y fuerzas multinacionales $y_{\text {, }}$ por supuesto, con las necesidades de carácter estrictamente nacional. De acuerdo a la directriz política plasmada en la DDN 1/04, estamos trabajando para mantener el nivel de protagonismo en la PESD alcanzado en el primer ciclo de planeamiento de capacidades europeas, correspondiente al HHG.

Por su especial interés para nuestras Fuerzas Armadas, quisiera hacer referencia a dos aspectos específicos reflejados en el HLG 2010 de una manera más detallada.

\section{Iniciativa Grupos de Combate UE (BATTLEGROUPS) - Fuerzas de Respuesta Rápida}

La necesidad de dotarse de una capacidad de despliegue de fuerzas militares de alta disponibilidad, que permita la ejecución de operaciones de respuesta rápida, es uno de los objetivos que la UE estableció para el cumplimiento de los nuevos cometidos surgidos de la PESD. El Objetivo General de Helsinki, aprobado por el Consejo Europeo a finales de 1999, ya identificaba este aspecto dentro de la lista genérica de capacidades militares necesarias para la puesta en marcha de operaciones de gestión de crisis lideradas por la UE ${ }^{17}$.

Sin embargo, han hecho falta varios años para poder hacer frente eficazmente a esta necesidad. El Concepto BATTLEGROUPS (BGs) de la UE fue aprobado en junio de 2004, tras una iniciativa trilateral de Francia, Alemania y el Reino Unido presentada a principios de ese año. Los BGs son una fuerza conjunta, aunque muy orientada a operaciones terrestres, que constituyen una de las posibles opciones de la UE para la oportuna provisión de las capacidades militares necesarias en una operación de gestión de crisis, con necesidad de repuesta rápida. Se trata de una fuerza de dimensiones reducidas, "la mínima fuerza militar creíble", capaz de realizar las Ilamadas misiones "Petersberg ampliadas"18 que la UE ha asumido. Con ella, lógicamente, no se trata de competir, sino de complementar, a otras capacidades ya existentes en nuestro entorno como las Fuerzas de Respuesta de la OTAN (NRF), en las que también participa nuestro pais y que son fuerzas de una mayor magnitud y concebidas para otro tipo de misiones.

El período de capacidad operativa inicial (IOC) de esta iniciativa europea comenzó en enero de 2005. Durante el mismo, las exigencias operativas y el nivel de ambición establecido era ligeramente más bajo que el actual, una vez alcanzada la capacidad operativa plena (FOC) en enero de $2007^{19}$.

La iniciativa BGs de la UE ha sido recibida con un alto nivel de compromiso entre los Estados miembros de la Unión. Durante la Conferencia de Compromiso de Capacidades Militares, celebrada en Bruselas en noviembre de 2004, se hizo oficial la oferta de trece BGs disponibles durante el período 2005-2007, así como una indicación de aquellos que podrían estar disponibles a partir del año 2008. Las Fuerzas Armadas españolas, participan en tres de estos agrupamientos, liderando dos de ellos.

\section{- BG anfibio, basado en la Fuerza Anfibia Hispano-Italiana (SIAF).}

Esta unidad, en la que además de España e Italia han participado con fuerzas Grecia y Portugal, estuvo en servicio durante el primer semestre de 2007, contribuyendo con su experiencia y lecciones aprendidas a la consecución de la FOC del concepto Battlegroup. Este BG ha sido ofertado de nuevo, para el período de alerta correspondiente al primer semestre del año 2009, aunque en esta ocasión el liderazgo de la unidad lo ejercerá Italia.

- BG "Nación Marco" español, basado en un Batallón de Infantería Ligera, con participación de Francia, Alemania y Portugal.

Ha sido ofrecido para su eventual empleo durante el primer semestre de 2008. A lo largo del año 2005, se han firmado una serie de Declaraciones Conjuntas entre España, Francia y Alemania por las que se ha establecido el marco genérico de participación (en términos de capacidades) en este BG. En reciprocidad se ha fijado la participación de España en el BG basado en la Brigada 
Franco-Alemana (BFA). Durante el pasado año 2006 se ha llevado a cabo la negociación de los Acuerdos Técnicos que regulan la participación en dichos BGs.

Debe señalarse que, a finales de 2005, se produjo el acuerdo político entre España y Portugal que va a permitir la participación de medios militares portugueses en el BG liderado por España.

- Participación en el BG basado en la BFA, ampliado a países del Eurocuerpo (Bélgica y Luxemburgo).

El proceso de participación sigue las mismas pautas indicadas para el caso anterior. Este BG ha sido ofrecido para su eventual empleo durante el segundo semestre de 2008.

Desde una perspectiva militar, no puede caber duda del efecto positivo que esta iniciativa está teniendo en el ámbito europeo. La iniciativa ha sido acogida con gran interés por los Estados miembros y los compromisos iniciales, formulados en noviembre de 2004, permitian cubrir las necesidades hasta el año 2009. Actualmente, el calendario de fuerzas en alerta está prácticamente cubierto hasta el año 2011. Podríamos añadir, como conclusión, que de una forma similar al efecto transformador que el concepto NRF ha producido en el ámbito OTAN, esta iniciativa está suponiendo un tremendo aliciente para favorecer la transformación de las FAS de algunos Estados miembros de la $U E$, en aras de obtener una capacidades militares más eficientes e interoperables.

\section{Dimensión marítima de la PESD e iniciativa aérea de respuesta rápida}

En la reunión informal de Directores Generales de Política de Defensa europeos, celebrada en Luxemburgo en febrero de 2005, España presentó un documento de trabajo que dio origen a un estudio sobre la Dimensión Marítima de la Unión Europea, por la convicción de que el proceso de desarrollo de capacidades militares de la UE no podía centrarse únicamente en el desarrollo de agrupamientos orientados a operaciones terrestres (BGs). Los resultados iniciales del estudio, presentados a finales de 2006, suponen el primer paso de un proceso conducente al establecimiento de un mecanismo que permita a la UE generar fuerzas navales para operaciones de respuesta rápida. Al mismo tiempo, el estudio ha dejado abierta la puerta para el fortalecimiento de la cooperación interpilares en el campo de la Protección Marítima ${ }^{20}$.
Del mismo modo, durante el pasado año, comenzaron los estudios para generar un mecanismo que garantice a la UE contar la capacidad de realizar operaciones aéreas de respuesta rápida. La iniciativa se encuentra todavía en sus fases iniciales y, al igual que la Dimensión Marítima, busca establecer un mecanismo adecuado de generación de este tipo de fuerzas, que sea coherente con el concepto Battlegroup y que no suponga un esfuerzo adicional a los Estados miembros.

España ha tomando una actitud activa, en la línea de mantener la coherencia con el impulso inicial realizado en materia de capacidades militares. Todas las iniciativas que se pongan en marcha en relación a este asunto deben, desde nuestra óptica nacional, estar íntimamente coordinadas con la vista puesta en el horizonte de un concepto más global de Fuerzas de Respuesta de la UE.

\section{Mirando al Futuro}

\section{Visión a largo plazo de la Unión Europea (EU LTV)}

La Agencia Europea de Defensa (EDA) y el EUMC pusieron en marcha sendas iniciativas ${ }^{21}$, a lo largo del año 2005, que han confluido en la elaboración de un estudio prospectivo a largo plazo (año 2030) para identificar las capacidades que podrá requerir la UE y el tipo de operaciones en las que podrá participar en un horizonte posterior a la consecución del Objetivo Global $2010^{22}$. Tres son los objetivos que se perseguían: elaborar un documento abierto, que constituyera la base para la definición de las futuras capacidades que requerirá la PESD, contribuir a la armonización de requisitos y desarrollar una estrategia europea de investigación y tecnología en materia de defensa.

El resultado ${ }^{23}$ es un interesante análisis prospectivo, con algunos puntos controvertidos y que no ha llegado a satisfacer todas las expectativas que de él se esperaban. No obstante, se trata de un documento vivo, que constituye uno de los puntos sobre los que se pretende basar el desarrollo de análisis más detallados y profundos de las capacidades militares que se requerirán en el futuro. Debe señalarse que ha producido un resultado de gran trascendencia como es la elaboración del primer estudio prospectivo global sobre tendencias, factores y actores 
que contribuirán a definir el sistema internacional en el que deberá actuar la Unión Europea ${ }^{24}$, cuyas conclusiones abren un amplio campo para la reflexión en materias de seguridad y defensa.

\section{Posible puesta en marcha de elementos contemplados en el Tratado Constitucional}

La Presidencia Alemana del Consejo de la UE, ha incluido entre sus objetivos para el primer semestre de 2007, la revitalización del proceso constitucional europeo. De producirse, la entrada en vigor del Tratado Constitucional va a suponer una serie de reformas cruciales para el futuro de la PESD. La de mayor trascendencia, a nuestro entender, es que el Tratado Constitucional prevé la creación del puesto de Ministro de Asuntos Exteriores encargado de formular e implantar la política Exterior y de Seguridad Común. El titular del cargo será al mismo tiempo Vicepresidente de la Comisión y cabeza de la Agencia Europea de Defensa y, para el ejercicio de sus funciones, dispondrá de un Servicio de Acción Exterior (EEAS).

Establecer esta nueva figura ministerial tendrá varias consecuencias importantes. La primera es que los futuros Embajadores de la UE probablemente reemplazarán a los actuales Representantes Especiales del Secretario General en zonas de crisis y pasarán a desempeñar un papel relevante en caso de misiones u operaciones. Asimismo, dado que la Gestión de Crisis será una de las principales responsabilidades del futuro Ministro de Exteriores, el EUMS podría obtener un papel más relevante, en lo que respecta a sus órganos de apoyo. Finalmente, el nuevo Ministro presidirá las reuniones del Consejo de la UE, en su formato de Asuntos Generales y Relaciones Exteriores (CAGRE), poniendo fin al sistema actual de Presidencias rotatorias semestrales en el ámbito PESC, en el que se incluyen las materias de Seguridad y Defensa.

La inclusión de organismos militares en apoyo del EEAS y los cambios en el CAGRE, debe verse acompañado por el desarrollo de relaciones más profundas de los Ministros de Defensa de los países miembros con los organismos de la UE. A este respecto, no debería perderse de vista la posibilidad de establecer una nueva configuración de Consejo de la UE en la que se incluya un formato propio para los Ministros de Defensa. Esto permitirá continuar progresando hacia una política de Defensa Común y equilibrar el peso que en área de Seguridad y Defensa europea se atribuye a los Ministerios de Asuntos Exteriores.

Debemos incluir en este somero análisis del Tratado Constitucional, una mención a una nueva herramienta que consideramos fundamental para hacer realidad la política común de Defensa en la UE: el mecanismo de cooperación estructurada permanente. Esta figura supondrá la apertura de una nueva etapa en el desarrollo de la PESD, ya que permitirá un progresivo avance en cuestiones de defensa, incluyendo las operaciones más exigentes, por aquellos países europeos que quieran ir más rápido y más lejos. Este avance de unos, mantenido bajo la dirección de las instituciones europeas, permitirá animar a otros Estados miembros más reticentes -a través de la visibilidad del proceso y de la confianza en sus mecanismos de control- a incorporarse a las diferentes iniciativas y la implantación final de una eficaz política común de Defensa en el ámbito de la UE.

\section{ConcLusión}

En el período transcurrido desde Maastricht, no parece exagerado decir que se ha cerrado un ciclo. En efecto, una vez elaborado casi por completo el marco doctrinal, llevadas a cabo las primeras operaciones tanto de forma autónoma como apoyándose en estructuras OTAN, estando en marcha el proceso de desarrollo de los nuevos catálogos de medios y capacidades militares, y con el cúmulo de nuevas iniciativas institucionales aprobadas en el texto del Tratado Constitucional, tenemos a la vista un horizonte abierto y diferente.

Abierto, por la progresiva puesta en marcha de la Agencia Europea de Defensa y por la posibilidad de poner en marcha ciertos aspectos contemplados en el Tratado Constitucional, referidos a la PESD, aun cuando éste no sea ratificado. Diferente, porque a los aspectos ya indicados se suman otros en curso, como por ejemplo las estructuras específicas de la UE para conducción de operaciones -a partir de la CIV-MIL Cell-, y las fuerzas de respuesta rápida (BGs), iniciativas ambas que, aunque modestas, darán visibilidad a la voluntad de la UE de convertirse en un actor de carácter global también en asuntos de seguridad y defensa. 
En el ámbito de futuras actuaciones, parece que la UE busca materializar su influencia mediante la intervención, bajo el mandato de las Naciones Unidas, en diferentes espacios geográficos. Asi, aunque como ya hemos comentado, la acción europea se extiende por todo el globo, el continente africano se perfila como uno de los espacios donde la UE desarrollará sus posibilidades, mediante la ejecución de operaciones empleando medios militares y civiles, en las que será frecuente actuar en apoyo a otras organizaciones como la Unión Africana o las propias $\mathrm{Na-}$ ciones Unidas.

Todo ello sin olvidar nuestro "patio trasero"25 europeo. La dolorosa lección de los Balcanes, en cuya estabilización aún estamos empeñados, nos muestra que los conflictos no han desaparecido en nuestro continente. Por ello, no en vano, la EES incluye específicamente en su objetivo de "vecindad segura", la estabilidad en los paises vecinos del Este europeo, lo que conlleva a la prevención de poten-

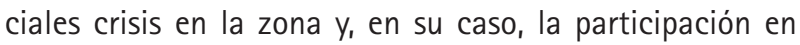
su gestión mediante acciones de las que ya hemos mencionado algún ejemplo ${ }^{26}$.

En el ámbito institucional, existe una preocupación creciente por el papel de lo militar en el marco de los distintos foros que conforman el mecanismo de toma de decisiones PESD. El Comité Militar de la UE (EUMC) pierde relevancia paulatinamente, aunque su formato, en sesión de Jefes de Estado Mayor de la Defensa, le confiere un valor asesor a los Ministros de Defensa indiscutible. Pero, el nacimiento de la EDA -si no se logra definir con claridad el reparto de competencias entre ambos organismos- le puede restar un área significativa de responsabilidad en el campo de la definición y desarrollo de capacidades militares. Por otra parte, el EUMS -que no olvidemos nació en Niza fundamentalmente para apoyar al EUMC- se va librando -al amparo de la Secretaría General del Consejo, donde está encuadrado orgánicamente-del apoyo al EUMC y se perfila como otro interlocutor militar en la UE. Lejos de ser motor, el EUMC va quedando así relegado, en su faceta de dirección de todas las actividades militares en el ámbito de la UE, tal y como marcan sus Términos de Referencia ${ }^{27}$. Asimismo, pensamos que una de las claves para el futuro del EUMC estará en la forma en que la posible puesta en marcha del Servicio de Acción Exterior de la UE afecte al encuadramiento, competencias y relaciones de dependencia de los distintas estructuras militares permanentes en el seno de la UE.
Desde una perspectiva nacional, la implantación del acervo PESD en el ámbito militar es un tema en el que debemos seguir progresando, con una vocación de estabilidad en el tiempo. A la luz del análisis de lo aprendido en estos años, cabría plantearse también un análisis de algunas estructuras nacionales, con el objeto de reajustarlas frente a las nuevas perspectivas $y$, muy en particular, teniendo en cuenta el enfoque global cívico-militar que la UE está poniendo en marcha a través de recientes documentos aprobados. La potencial repercusión de este enfoque en otros organismos del Ministerio de Defensa -e incluso en otros Ministerios- con responsabilidades propias en el ámbito de la PESD, no debe minimizarse.

El nuevo ciclo de la PESD se solapa con el proceso de transformación de nuestras FAS. Determinadas acciones en curso -como la oferta nacional a la iniciativa BGs UE-, deben ser utilizadas en un sentido que ayude y estimule el asentamiento del modelo de Fuerzas Armadas en el que la acción conjunta se consolide, como pauta natural de trabajo. De forma similar, deberán aprovecharse las conclusiones que se extraigan de los trabajos en materia de capacidades y operaciones futuras, más allá del horizonte planteado por el HLG 2010, que serán aplicadas, en lo posible, al proceso nacional de planeamiento de fuerzas.

Finalmente, la participación de España en fuerzas multinacionales podría ser objeto de análisis desde la óptica de la racionalización y optimización del esfuerzo. Del anhelo de mejorar la cooperación militar entre las naciones europeas, ante la ausencia de un marco genérico común, surgieron en su día diferentes iniciativas y fuerzas multinacionales en las que España participa activamente. Tal vez el desarrollo de la PESD permita replantear la orientación de algunas, tratando de especializarlas según los cometidos y exigencias definidos en el Objetivo General de Fuerza 2010.

Me permito acabar estas líneas con un mensaje optimista. La Unión Europea se está erigiendo como actor de primer orden en el ámbito de la seguridad internacional, gracias a sus capacidad intrínseca para articular actuaciones de carácter civil, económico, diplomático y militar, en materia de gestión de crisis. Tal y como contempla en su conclusión la Estrategia Europea de Seguridad, una Europa más activa y capaz estará en situación de contribuir 
a un mundo más justo y seguro. En este empeño global, hay un claro campo de acción militar. Por nuestra parte, somos conscientes de nuestras posibilidades, trabajamos para mejorarlas y estamos orgullosos de emplearlas en beneficio de nuestra sociedad y de la construcción de Europa.

\section{NOTAS}

1 Para mayor detalle ver, del mismo autor: "Panorama de la conflictividad internacional" - PANORAMA ESTRATÉGICO 2005/2006 (Ministerio de Defensa en colaboración con el Real Instituto Elcano).

2 Secretario General del Consejo y Alto Representante de la UE para la PESC (SG/AR).

3 Una Europa segura en un mundo mejor. Estrategia Europea de Seguridad, Bruselas, 12 de diciembre de 2003.

4 FFM: Fact Finding Mission.

5 DDR: Disarmament, Demobilisation and Reintegration.

6 SSR: Security Sector Reform.

7 Aceh Monitoring Misión (AMM), puesta en marcha a mediados de 2005.

8 Misión Just-Themis de reforma del sistema judicial en Georgia. Misión COPPS de apoyo a la Policía Palestina y la Misión desarrollada en el paso fronterizo de RAFAH en la franja de Gaza.

9 El planeamiento integral (comprehensive planning), hace énfasis en el nuevo marco de planeamiento exigido para la coordinación cívico-militar en el ámbito de las operaciones de gestión de crisis lideradas por la UE y que hagan uso simultáneo de medios civiles y militares (EU Concepf for Comprehensive Planning - Council doc. 3983/05, de 3 nov. 2005).

10 La propuesta de crear un Cuartel General permanente para operaciones de la UE, fue rechazada por la oposición a crear estructuras permanentes de mando y control que supusieran un incremento del esfuerzo de los estados miembros y que podrian entenderse como una duplicación innecesaria de las estructuras existentes en la OTAN, en un momento en el que ésta se estaba planteando la necesidad de reducirlas.

11 Llevadas a cabo en la República Democrática del Congo durante el año 2003 con el objetivo de ayudar de forma temporal a las fuerzas ONU en la región de ITURI evitando el peligro de una creciente desestabilización mientras se incrementaba las fuerzas de MONUC en el pais.

12 "Advance Planning", en su faceta de planeamiento de contingencia a nivel estratégico militar y político-militar. Este tema está todavía pendiente de ser desarrollado conceptualmente en el ámbito PESD.

13 Su formato de mayor nivel lo componen los Ministros de Defensa de los Estados miembros (excepto Dinamarca) y un representante de la Comisión (Council Joint Action 2004/551/CFSP, de 12 jul. 2004).

14 Sugerencias sobre unos procedimientos integrales y coherentes de la UE para gestión de crisis (Suggestions for procedures for coherent, comprhensive EU crisis management, Council Doc. 11127/03, de 3 jul. 2003). Su propio nombre deja claro el carácter flexible de su aplicación, que curiosamente contrasta con el detalle y complejidad de los mismos.

15 Informe del SG/AR sobre un proceso abreviado de planeamiento y toma de decisiones para operaciones de
Recibido: 9 de enero de 2008 Aceptado: 12 de marzo de 2008 
respuesta rápida de la UE (Council Doc. 7317/05, de 15 mar. 2005).

16 EU emergency and crisis co-ordination arrangemenfs (Council Doc. 15106/05, de 29 nov. 2005), presentados en el Consejo de Asuntos Generales y de Relaciones Exteriores de la UE a finales de 2005.

17 Para mayor información, ver "Grupos de Combate UE: una apuesta europea en materia de gestión de crisis", Revista Ejército, ene.-feb. 2006.

18 Misiones "Petersber" son las incluidas en el artículo 17/2 del vigente Tratado de la Unión Europea (misiones humanitarias y de rescate, misiones de mantenimiento de la paz y misiones en las que intervengan fuerzas de combate para la gestión de crisis, incluidas las misiones de restablecimiento de la paz) que han sido ampliadas por la EES para in- cluir misiones de desarme, reforma del sector de seguridad o actuaciones en el marco de la lucha contra el terrorismo.

19 El nivel de ambición que la UE se ha impuesto es el de estar en condiciones de mantener dos operaciones militares de respuesta rápida de forma simultánea (limitada a una durante la IOC).

20 Protección Maritima (Maritime Security): Se podría definir como aquellas medidas encaminadas a detectar, conocer y contrarrestar todas aquellas amenazas que desde el entorno marítimo puedan atentar contra la seguridad de la población, la estabilidad de la sociedad, el progreso económico y en general contra nuestros intereses y los de nuestros aliados.

21 "EDA Long Term Vision" y "EUMC: Post 2010 an EU milifary vision".
22 Decisión del Comité Director de la EDA de 21 de noviembre de 2005 sobre LTV.

23 "An initial Long Term Vision for European Defence Capability and Capacity Needs", disponible en http://www. eda.europa.eu/ltv/ltv.htm

24 Institute for Strategy Studies, The New Global Puzzle. What World for the EU in 2025?, Paris, 2006.

25 Expresión empleada para referirse a los países del Este europeo y de la cuenca mediterránea vecinos de la UE, por el entonces Presidente de la Comisión Europea Sr. Romano Prodi en su discurso en la sexta conferencia ECSA-World celebrada en Bruselas en diciembre de 2002.

26 Diferentes misiones en paises Balcánicos, Moldavia y el Cáucaso.

27 Decisión del Consejo de 22 de enero de 2001 (2001/79/CFSP). 